\title{
Capacity Utilization in Small-Scale Fisheries: A Case of the Sultanate of Oman
}

\author{
Mohammed Al Siyabi* and Shekar Bose \\ Department of Natural Resource Economics, College of Agricultural and Marine Sciences, Sultan \\ Qaboos University, Oman \\ *Corresponding author (m.s.alsiyabi@gmail.com) \\ iD https://orcid.org/0000-0002-7043-802X
}

\begin{abstract}
The interrelated issues of capacity utilization (CU) and technical efficiency (TE) have received global importance as they relate to the problem of overcapitalization and overfishing. Given the limited research on these issues in the context of small-scale fisheries, this paper attempts to provide empirical estimates of TE and CU with particular focus on small-scale fisheries in Oman using Data Envelopment Analysis (DEA). The output variables included aggregated catch of three fish categories namely large pelagic, demersal, and other, while the boat length, engine power and number of crews were used as input variables in the empirical analysis. The data for the year 2010 were used and 97 active fishing boats were selected for the analysis. The TE and CU estimates were generated under the assumption of constant returns to scale (CRS) and variable returns to scale (VRS). The TE estimates under both CRS and VRS assumptions indicate that about $84.5 \%$ and $79.4 \%$ of the representative boats are operating in a technically inefficient manner. In addition, the unbiased CU estimates under the same assumptions show that about $77.3 \%$ and $82.5 \%$ of the boats are not operating at full capacity. Furthermore, the average score of unbiased CU measure suggests that the representative boats may not be using variable inputs efficiently. To gain a better understanding of harvesting operations in small-scale fisheries sector in the country, it is prescribed that the management authority should extend this study for other coastal governorates and investigate the potential causes of inefficiency to design effective management strategies.
\end{abstract}

Keywords: Small-scale fisheries, technical efficiency, capacity utilization, Data Envelopment Analysis (DEA), Sultanate of Oman.

\section{INTRODUCTION}

In the context of small-scale fisheries in developing countries, concerns related to overfishing and overcapacity have been widely recognized (Purcell and Pomeroy 2015; Pomeroy 2012; Salas et al. 2007) and weak governance and poor management, amongst others, were identified as driving forces of such concerns. Failure to address such concerns will have adverse socio-economic consequences as small-scale fisheries supply income and food to millions of families worldwide (FAO 2017). To effectively address these interrelated concerns fishery managers must have information about the existing level of fishing capacity in a fleet. In addition, excess capacity in fisheries leads to inefficient use of economic resources which undermines the economic performance of smallscale fisheries. On the other hand, overcapacity in fisheries creates excessive pressure on wild stocks. However, it is noted from the literature that quantitative information on small-scale fisheries in developing countries in relation to economic performance and capacity utilization (CU) is limited compared to commercial fisheries (Pomeroy 2012; Salas et al. 2007). This is perhaps due to financial constraints and lack of necessary data for such analysis.

These issues are of strategic importance to smallscale fisheries of the Sultanate of Oman. In the Sultanate of Oman the fisheries sector is at the core of national development agenda and substantial efforts have been directed by the management authority to optimize socio-economic benefits from the sector through improving fleet performance and fisheries governance mechanisms as reflected in the five-year plan (MNE 2007a). Small-scale fisheries have been playing a vital role in the enhancement of socio-economic welfare, including food security (MNE 2007a, 2007b; Bose et al. 2010). In 2016, small-scale fisheries contributed about $99 \%$ to total landings (277,014 tonnes) and provided direct 
employment (full-time and part-time) to about 47,470 fishers (MAF 2017). In this regard, longterm sustainability of the sector is of paramount importance and to make meaningful progress towards the achievement of long-term sustainability the above-mentioned concerns must be addressed. It is also noted that the issue of overfishing is confronting small-scale fisheries in the Sultanate of Oman (Al-Balushi et al. 2016; Bose et al. 2017), and capacity and $\mathrm{CU}$ is a major concern for fisheries authority.

Small-scale fisheries in the Sultanate of Oman are characterized by: 1) a wide range of landing sites along the coastline; 2) a low level of capital investment and labor intensive production; 3) the use of traditional knowledge and application of traditional rules (locally called Senat Al-Bahar); 4) the harvest of multiple species using multiple gears; 5) the seasonal use pattern of fisheries resources; 6) a lack of bargaining power of fishers to influence market price; and 7) the contribution to food security, employment generation and foreign exchange earnings. These characteristics are common in small-scale fisheries around the world (Salas et al. 2007).

Fishing capacity as stated by the United Nation Food and Agricultural Organization (FAO) is "the maximum amount of fish over a period of time (year, season) that can be produced by a fishing fleet if fully utilized, given the biomass and age structure of the fish stock and the present state of technology" (FAO 2000). The concept of capacity utilization (CU) indicates the difference between the actual and potential output given the existing level of fixed input in normal operating conditions (Johansen, 1968) and is measured by the ratio of observed output to potential output (Dupont et al. 2002). On the other hand, technical efficiency (TE) that relates to fishing capacity and capacity utilization in fisheries represents the degree to which vessels are performing relative to other vessels using similar levels of inputs (FAO 2000; Guttormsen and Roll 2011).

In evaluating relative efficiencies for a group of Decision-Making Units (DMUs), Data Envelopment Analysis (DEA) -a non-parametric linear programming method-is widely used. DEA is popularized by Charnes et al. (1978) and later extended by Banker et al. (1984), has become one of the promising areas in operations research for performance measurements and evaluation and its application can be found in various discipline areas (Emrouznejad and Yang 2018). DEA is also used in analyzing the extent of technical efficiency, measuring capacity utilization, and benchmarking for reducing excess capacity in fisheries. For instance, in the context of commercial fisheries the application of DEA can be found in Duy and Flaaten (2016), Tidd et al. (2016), Yang and Lou (2016), Collier et al. (2014), Ceyhan and Gene (2014), Vázquez-Rowe and Tyedmrs (2013), Tsitsika et al. (2008), Pascoe and Tingley (2006), Guyader and Daurès (2005), Kirkley et al. (2003), Tingley et al. (2003), and Vestergaard et al. (2003). On the other hand, in the context of small-scale fisheries the application of DEA can be found in Gigentika et al. (2016), Castilla-Espino et al. (2014), Pham et al. (2014), Shen and Shen (2013), Zibaei (2012), and Madau et al. (2009). Based on this brief review of literature, the present study uses DEA as the approach requires neither a priori determination of a production function nor information on prices (Odeck, 2000) and it is claimed to be useful in identifying the best performer (Ross and Droge 2002) as well as dealing with multiple inputs and outputs simultaneously (Kirkley et al. 2002).

With this background, the main objective of this case study is to provide empirical estimates of TE and $\mathrm{CU}$ with reference to small-scale fisheries of Dhofar Governorate, one of the eight coastal Governorates of the Sultanate of Oman.

\section{MATERIALS AND METHODS}

\section{Study area}

The study was conducted in Dhofar Governorate (between latitudes $16^{\circ} 42^{\prime}$ and $20^{\circ} 00^{\prime}$ North and longitude $52^{\circ} 00^{\prime}$ and $56^{\circ} 24^{\prime}$ East) located in the southern part of the Sultanate of Oman (Fig. 1). The study site was selected due to its resource potential. It is the largest Governorate in terms of size $(99,300$ $\mathrm{km}$ ) in the Sultanate of Oman with ten provinces of which seven are coastal provinces. The meteorological conditions in Dhofar Governorate are diverse, ranging from very hot to cool conditions, this makes rich in resources with seasonal monsoon winds providing an advantageous natural marine ecosystem. The coral reef, sea grass and seaweed found along the coast of the governorate provide a good shelter and diet for marine species (Burt et al. 2016; MECA 2015). In 
addition, the Governorate hosts nine coastal lagoons (khawrs) which provide sanctuaries for species as they are used as breeding areas and nursery grounds for young marine life (Burt et al. 2016).

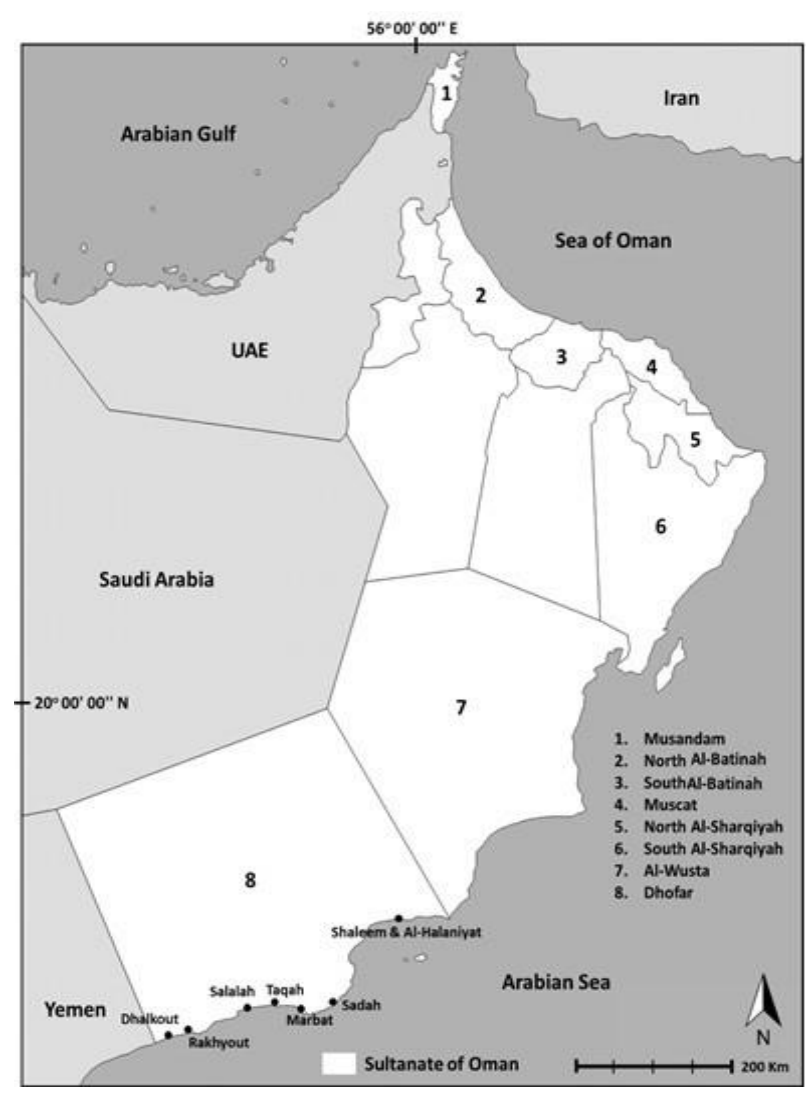

Fig. 1 Map of the Sultanate of Oman

The Sultanate of Oman's fisheries are categorized by target species, grouped into five major categories namely large pelagic species (such as, yellowfin tuna, longtail tuna, large jacks, kawakawa, kingfish etc.) and demersal species (such as, emperor, seabream, grouper, croaker etc.), small pelagics (such as, sardine, Indian mackerel, anchovy, small jacks), sharks and rays, and crustaceans (such as, lobster, shrimp, abalone). The total fish landings in Dhofar increased from 18,537 tons in 2005 to 43,077 tons in 2016, with an average growth rate of $7.97 \%$ and the growth is dominated by demersal and large pelagic species. During the same period, the gross value increased from about $\$$ 28.5 million to $\$ 78.6$ million with an average growth rate of $9.66 \%$. The fishing fleet is dominated by fiberglass boats and there are about 4,614 registered artisanal fishing boats - that represents
$20 \%$ of total boats in the Sultanate of Oman. Smallscale fishers conduct daily fishing trip in coastal waters and harvest multiple species using multitudes of fishing gears such as handlines, gill nets, longlines, traps, troll lines, beach seines and cast nets etc. (MAF, 2017; Bose et al. 2017).

\section{Empirical model}

Following the suggestion by the FAO (2000), this study adopted the output-oriented DEA approach to estimate TE and CU using boat-level data. The output-oriented approach determines the maximum possible expansion of output with no change in the fixed factors of production (i.e., inputs). The inputs are divided into fixed inputs $(\alpha)$ and variable inputs $(\alpha)$. The estimation of fishing capacity requires solving the following model consisting of equations (1) to (6) (hereafter termed as Model A):

$\operatorname{Max} \theta_{1}$

\section{Subject to:}

$\theta_{1} u_{j m} \leq \sum_{j=1}^{J} z_{j} u_{j m} m=1,2, \ldots . . M$,

$\sum_{j=1}^{J} z_{j} x_{j n} \leq x_{j n} \quad n \in \alpha$,

$\sum_{j=1}^{J} z_{j} x_{j n}=\lambda_{j n} x_{j n} \quad n \in \dot{\alpha}$,

$z_{j} \geq 0, \quad j=1,2, \ldots \ldots \ldots, J$,

$\lambda_{\text {jn }} \geq 0$

$n \in$ ó,

where, $\theta_{1}$ is the capacity score, $u_{j m}$ is the amount of output $\mathrm{m}$ produced by the boat $\mathrm{j}, x_{j n}$ is the quantity of input $\mathrm{n}$ used by the boat $\mathrm{j}, z_{j}$ is the intensity variable for the boat $\mathrm{j}, \lambda_{j n}$ is the input utilization rate by the boat $j$ of variable input $n$.

Model A describes a production function that operates under constant returns to scale (CRS) and reflects the fact that output will change by the same proportion as inputs are changed. It is assumed that each boat uses non-negative amount of each input to produce non-negative amount of each output. Equation (2) represents one constraint for each output, while equation (3) constraints the set of fixed inputs. Equation (4) allows the variable input to be unconstrained. Equation (5) represents the nonnegativity condition on the $\mathrm{z}$ variable while equation (6) denotes the non-negativity condition for the input utilization rate.

Model A can be extended to incorporate variable returns to scale (VRS) -that encompasses both increasing and decreasing returns to scale- by adding the following convexity constraint: 
$\sum_{j=1}^{j} z_{j}=1$

Capacity output is determined by multiplying $\theta_{1}$ by observed production $(\mathrm{u}$ ) for each output and $\mathrm{CU}$ can be calculated as follows:

$\mathrm{CU}($ observed $)=\frac{u}{\theta_{1} * u}=\frac{1}{\theta_{1}}$

This CU measure is a ray measure of $\mathrm{CU}$ which may be biased downward because the observed output may not be produced in a technically efficient manner (Färe et al. 1994). To correct this bias the following DEA model (hereafter termed as Model B) needs to be solved by constraining both the fixed and variable inputs to their current levels. It should be noted that Model B will also measure TE and the outcome $\theta_{2}$ represents the amount by which production can be increased if production is technically efficient.

$\operatorname{Max} \theta_{2}$

Subject to:

$\theta_{2} u_{j m} \leq \sum_{j=1}^{J} z_{j} u_{j m}, m=1,2, \ldots, M$,

$\sum_{j=1}^{J} z_{j} x_{j n} \leq x_{j n}, \quad n \in \alpha$,

$\sum_{j=1}^{J} z_{j} x_{j n} \leq \lambda_{j n} x_{j n} n \in \alpha^{\prime}$,

$z_{j} \geq 0 \quad j=1,2, \ldots J$.

TE can be calculated from Model B as follows:

$$
T E=\frac{1}{\theta_{2}}
$$

Now, using Models A and B unbiased CU measure can be estimated as follows:

$$
\mathrm{CU} \text { unbiased }=\frac{\theta_{2} * u}{\theta_{1} * u}=\frac{\theta_{2}}{\theta_{1}} \quad 0 \leq C U_{\text {unbiased }} \leq 1
$$

It should be noted that the value of $\mathrm{CU}<1$ indicates underutilization of full capacity $(\mathrm{CU}=1)$. The DEA model was estimated using in the general algebraic modeling system (GAMS) general optimization package.

\section{Data}

The present study used two types of survey data obtained from the Ministry of Agriculture and Fisheries (MAF). The data on species catch (weight) and gross values, fishing gears, duration of fishing trips, crew members, and fishing location were routinely collected by the MAF using the sampling procedure established by the FAO in 1980s. On the other hand, the data on boat characteristics such as boat ID, length, boat age, number of engines and horsepower were collected by the MAF in an ad hoc manner. In this study the data for species landings and gross values, gear types, duration of fishing trips (hours) and crew members were collected from 2010 survey whilst boat characteristics such as length (feet) and engine power (horsepower) were collected with matching boat ID from an ad hoc boat survey conducted in 2012.

Although the scrutiny of 2010 survey data revealed that fishing net was the dominant fishing gear $(58.8 \%)$, used for harvesting, there was no information on the number of net-pieces and netlength available. Therefore, it was decided not to use fishing gear as input variable in this study. Similarly, information on the true fishing time was not available and the recorded time in the survey data represents the trip duration which is used as one of the input variables in the model.

Scrutiny of 2010 survey data also revealed that boat ID was missing for a considerable number (about $91 \%$ of 5283 observations) of surveyed boats and the data were unbalanced with regard to the number of observations per boat which constrained the selection of sample size for the present study. The boats with missing ID and with the entry of zero catch of either large pelagic, demersal or other species categories were removed from the analysis. This process leads us to select 97 active boats for the empirical analysis and helps reducing the potential bias due to noisy observation in the data set (Holland and Lee, 2002). Although a legitimate question can be raised about the small sample size of the present study, the small sample size is not uncommon in DEA analysis (Madau et al. 2009; Vestergaard et al. 2003; Kirkley et al. 2002). Furthermore, the selection of sample size for the present study was constrained not only by the missing boat ID as stated above but also due to the lack of systematic and adequate boat level catch data for the year. However, the sample size $(\mathrm{N}=97)$ used in the study meet the 'degree of freedom' requirement which is as follows: the number of observation $(\mathrm{N})$ should be $\geq \max \{\mathrm{n} \times \mathrm{m}, 3(\mathrm{n}+\mathrm{m})\}$ where $\mathrm{n}=$ number of inputs and $\mathrm{m}=$ number of outputs in our model, this results in a minimum of 18 observations (Cooper et al. 2006).

Trip-level catch information was considered to estimate the average catch per fishing trip for the year 2010. The study used three inputs (boat length, engine power and crew members) and three outputs (average trip level catch of species comprising three categories; large pelagic, demersal, and others that involves the remaining species categories as 
mentioned earlier). Furthermore, the selection of the output and input variables is not uncommon in fisheries efficiency analysis. For example, species catch aggregation was conducted by Collier et al. (2014) and Tingley et al. (2005) and used as output variable in the DEA model. On the other hand, in the context of input measures, number of crew and engine power (hp) are used by Castilla-Espino et al. (2014), and vessel length is used by Tidd et al. (2016), amongst others.

\section{RESULTS}

The descriptive statistics of the input and output variables used in the analysis is presented in Table 1. It can be noted from Table 1 that the representative boats are relatively homogeneous with regard to boat length and crew members than engine power. The apparent heterogeneity in engine power reflects the choice made by individual fisher of using more than one engine with different horsepower. With regard to the output measures, noticeable variability is observed in all three cases with the lowest in large pelagic case followed by demersal and other categories. The largest fluctuation in other category is, perhaps, due to variability in seasonal small pelagic catch.

Table 2 presents the average score of capacity and efficiency parameters along with the average estimate of TE and CU (biased and unbiased) under both CRS and VRS assumptions for the year 2010. The mean estimates of capacity $\left(\theta_{1}\right)$ and efficiency $\left(\theta_{2}\right)$ parameters under both CRS and VRS assumptions are found to be theoretically consistent reflected by the fact that $\theta_{1} \geq \theta_{2} \geq 1$ (Pascoe and Tingley 2006). In addition, the mean TE score under VRS is higher than that of CRS. This result is in line with the theory as the presence of convexity constraint under VRS causes more boats to be identified as technically efficient. Furthermore, the mean TE estimates under both CRS and VRS indicate that the representative boats are on average operating in a technically inefficient manner.

It is also noted from Table 2 that the representative boats were at high $\mathrm{CU}$ under CRS as compared to VRS. The average $\mathrm{CU}_{\text {unbiased }}$ estimate for CRS (0.896) in Table 2 indicates that, if all representative boats work at full capacity level than the number of fishing trips required to harvest observed catch in the sample year 2010 would have been about $89.6 \%$ of the actual number of fishing trips observed. Therefore, the $\mathrm{CU}_{\text {unbiased }}$ measure indicates that boats are not using variable inputs (crew members) in an efficient manner.

Figures 2 and 3 illustrate the frequency distribution of capacity utilization and technical efficiency of the representative sample. It is estimated that $77.3 \%$ and $82.5 \%$ of the sample is operating below full capacity under both CRS and VRS assumptions respectively. With regard to TE score at boat level, it is noted that about $84.5 \%$ and $79.4 \%$ of the sample are operating in a technically inefficient manner under both CRS and VRS assumptions respectively. Based on this finding, it can be argued that a large proportion of sample boats are working in a relatively below the efficient production frontier.

Table 1 Summary of the input and output variables used in the analyses (Sample size, N=97)

\begin{tabular}{lcccc}
\hline & Min & Max & Mean & (S.D.) \\
\hline $\begin{array}{l}\text { Fixed Input } \\
\quad \text { Boat length (feet) }\end{array}$ & 17 & 25 & 21 & 2.542 \\
$\quad$ Boat power (HP) & 40 & 150 & 56 & 23.075 \\
$\quad \begin{array}{l}\text { Variable Input } \\
\quad \text { Number of crew (person) }\end{array}$ & 1 & 3 & 2 & 0.582 \\
$\begin{array}{l}\text { Output (Trip level) } \\
\quad \text { Catch of large pelagic (kg) }\end{array}$ & 0.330 & 178.900 & 28.933 & 35.705 \\
$\quad$ Catch of demersal (kg) & 4.390 & 193.750 & 66.636 & 50.264 \\
$\quad$ Catch of other fish (kg) & 0.500 & 495.460 & 51.930 & 101.460 \\
\hline
\end{tabular}


Table 2 Capacity and efficiency measure of small scale fisheries in the Sultanate of Oman (Sample size, $\mathrm{N}=97$ )

\begin{tabular}{lcccc}
\hline & \multicolumn{2}{c}{$\begin{array}{c}\text { Constant Returns } \\
\text { to Scale }(\text { CRS) }\end{array}$} & \multicolumn{2}{c}{$\begin{array}{c}\text { Variable Returns to } \\
\text { Scale (VRS) }\end{array}$} \\
\cline { 2 - 5 } & Mean & (S.D.) & Mean & (S.D.) \\
\hline Capacity $\left(\theta_{1}\right)$ & 2.854 & 2.372 & 2.435 & 2.081 \\
Efficiency $\left(\theta_{2}\right)$ & 2.401 & 1.674 & 1.740 & 1.126 \\
Technical Efficiency (TE) & 0.567 & 0.275 & 0.727 & 0.273 \\
Capacity Utilization (CU) & & & & \\
$\quad$ CU $_{\text {biased }}$ & 0.519 & 0.275 & 0.608 & 0.299 \\
CU $_{\text {unbiased }}$ & 0.896 & 0.119 & 0.835 & 0.229 \\
\hline
\end{tabular}
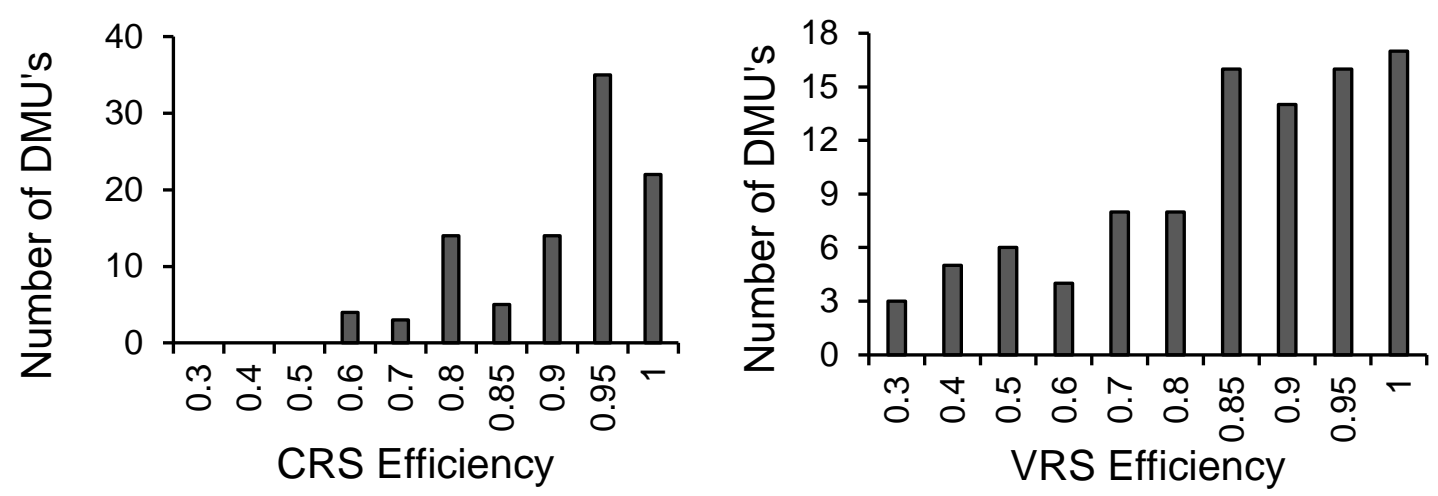

Fig. 2 The frequency distribution of unbiased capacity utilization measures
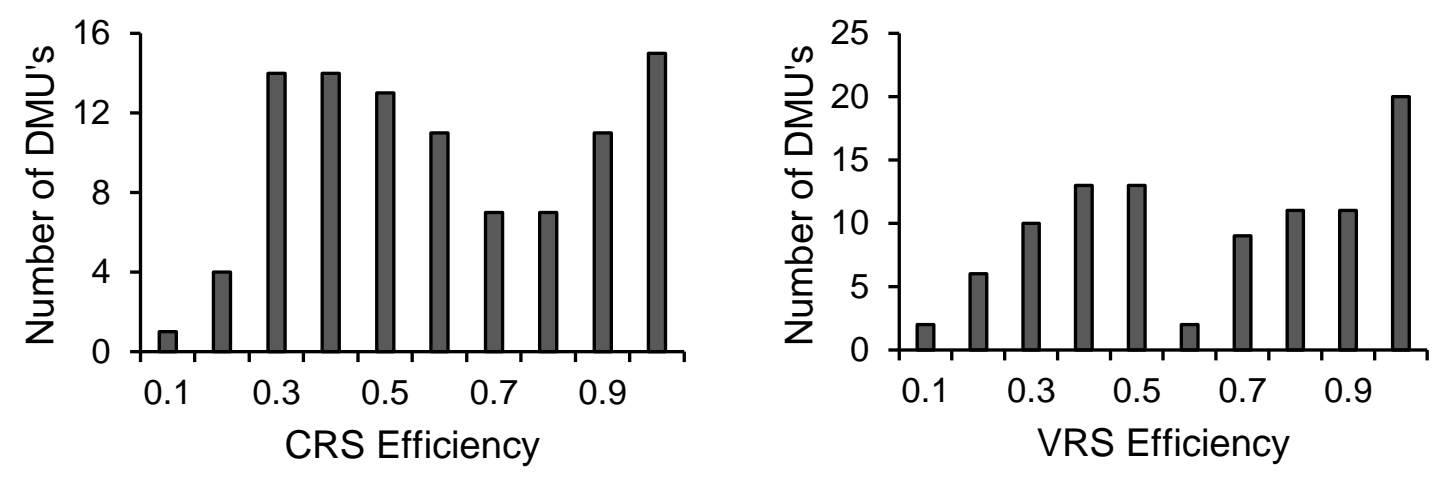

Fig. 3 The frequency distribution of technical efficiency measures

\section{DISCUSSION}

The apparent variation in output measures presented in Table 1, particularly in the case of 'other category', merits further discussion. The small pelagic landings are usually subject to seasonal influence. To capture this potential seasonal influence, the efficiency analysis should preferably use low frequency time series data such as monthly or quarterly or at least data comprising a number of years (Wu et al. 2013). This would certainly account for seasonal influence and may arrive at more precise results than the analysis currently conducted based on a single year. However, as mentioned earlier, a lack of low frequency data for the selected DMUs limits further investigation in this context. In the absence of such low frequency data future research should at least attempt to include more than 
a single year to investigate the pattern of potential change in efficiency scores.

However, it should be noted that it would not be appropriate to treat the high variation in catch data as 'noise' and address them accordingly by using sophisticated techniques such as bootstrapping and Monte Carlo simulations advocated in the literature (Desai et al. 2005; Zhang and Bartels 1998; ElDemerdash et al. 2016). The main reason is that the entries in the data set are real numbers and it is natural to treat the values as true observations that reflect the underlying true characteristics of smallscale fishing operations by fishers who are the real experts in making harvesting decisions to meet their objectives. Furthermore, the refinement of model estimates depends to a great extent on the level and adequacy of data which is simply non-existence for the case in hand which further diminishes the application of sophisticated techniques.

With regard to the sample size used in this study a legitimate question can be asked about its adequacy. In this regard, two important but related issues that deserve further attention. First, in relation to the issue of sample size adequacy it has been pointed out in the literature that there is an inverse relationship between the average TE score and the number of DMUs in the industry (Alirezaee et al. 1998). This suggests that as the number of DMU increases the average TE will tend to decrease. This indicates that the results generated in the present case study represent the upper limit of the efficiency estimates as it may deteriorate as the sample size increases. It is important to note that the main intention of the present study is not about the preciseness of the efficiency estimates but to determine whether inefficiency exists in harvesting operation of small-scale fishers which is echoed clearly in the results of the present study. More importantly, despite the potential upward biasness in the estimates, the prevalence of inefficiency has similar management implications and would demand for policy improvement. In addition, in DEA analysis it is difficult to produce highly refined estimate of efficiency as efficiency will vary from one moment to the next depending on the number of dominant fishers in the data set (Fig. 3). As indicated earlier, it is often infeasible and prohibitively expensive to collect adequate data for small-scale fisheries in developing countries to carry out empirical analysis using sophisticated techniques. Therefore, the requirement of adequacy of sample size must be compromised in the interest of practicalities.

Second, the DEA literature also highlighted the notion of dimensionality 'curse' arises from sample size inadequacy in relation to the number of input and output variables used in the DEA analysis (Zervopoulos 2012). However, the present study does not suffer from this problem as stated earlier the present study fulfils the 'degrees of freedom' requirement prescribed by Cooper et al. (2006).

However, there are a number of limitations of this paper that need to be stated. First, estimates provided are only for registered representative boats operating in Dhofar fisheries. Therefore, they should not be treated as an indication of inefficiency in the small-scale fisheries of the Sultanate of Oman. Second, the analysis was conducted for a single year which prohibits further investigation of change in efficiency pattern over time as mentioned earlier. Last but not least, the irregularity and inconsistency of boat-level survey data made it difficult to increase the sample size for the present analysis.

Despite these caveats, the information presented in this case study is rarely available for small-scale fisheries in the Sultanate of Oman. A particular implication of the results presented in this case study is that the relatively efficient operators can be nominated for benchmarking small-scale fisheries performance and would be useful for fisheries companies and traders to create a contractual agreement with efficient fishers to reduce supply uncertainty and increase economic returns to fishers.

Given the small-scale fisheries situation in the Sultanate of Oman, it seems the results for CRS are more appropriate as the deficiency in fishing operation at the optimal scale is unlikely to be influenced by factors such as imperfect information and financial constraints as suggested by Coelli et al. (2005). This may be supported by the fact that a majority of the traditional boats were relatively homogenous in terms of 'boat size' and 'crew members' (Table 1), operating in a competitive environment (as there are large number of boats in the fleet), have strong social networks among themselves and receiving financial support from the government.

\section{CONCLUSION}

This case study provided empirical estimates of TE and $\mathrm{CU}$ for a particular segment of small-scale 
fisheries in the Sultanate of Oman for the year 2010. To gain a better understanding of harvesting operations and performance of small-scale fisheries the management authority should extend this study by including other coastal governorates of the Sultanate of Oman. The authority should give priority to collect relevant boat-level primary data in a regular and consistent manner to conduct efficiency analysis for small-scale fisheries in the country.

Further study should be supported by the authority to investigate the potential causes of inefficiency and dynamic behaviour of fishers' performance so that effective strategies can be formulated to address the situation. For example, if technical inefficiency results from the lack of skills then the authority should provide appropriate training assistance to inefficient fishers to improve their economic performance or design exit strategies for inefficient operators in the fishery. Regardless of the stage of development in the fisheries sector in the Sultanate of Oman the issue of efficiency deserve careful attention to achieve its objectives stipulated in the strategic plan for the sector (MNE, 2007a).

\section{ACKNOWLEDGEMENTS}

The authors would like to thank the editor and anonymous reviewers for helpful comments and suggestions.

\section{REFERENCES}

Alirezaee, M.R., M. Howland and C. Van de Panne 1998. Sampling size and efficiency bias in data envelopment analysis. Advances in Decision Sciences 2(1):51-64.

Al-Balushi, A.H., S. Bose and A. Govender 2016. Stakeholders' Views on Management Arrangements: A Case of Kingfish Fishery in the Sultanate of Oman. Natural Resources 7(05): 251-264. doi: 10.4236/nr.2016.75022

Banker, R.D., A. Charnes and W.W. Cooper 1984. Some models for estimating technical and scale inefficiencies in data envelopment analysis. Management Science 30(9): 1078-1092.

Bose, S., H.S. Al-Masroori and A.M.H.A. Al-Habsi 2017. Traditional fisheries enforcement program: A case of three coastal villages in the eastern part of Oman. Marine Policy 78: 61-67. https://doi.org/10.1016/j.marpol.2017.01.001

Bose, S., A. Al-Mazrouai, S. Al-Habsi, I. Al-Busaidi and A. Al-Nahdi 2010. Fisheries and Food Security: The Case of the Sultanate of Oman. Proceedings of the International Conference on Food Security in the Arab Countries: New Challenges and Opportunities in the Context of Global Price Volatility, 2-4 March 2010, Sultan Qaboos University, Muscat.

Burt, J.A., S. Coles, H. van Lavieren, O. Taylor, E. Looker and K. Samimi-Namin 2016. Oman's coral reefs: A unique ecosystem challenged by natural and man-related stresses and in need of conservation. Marine Pollution Bulletin 105(2): 498-506.

Castilla-Espino, D., J.J. García-del-Hoyo, M. Metreveli and K. Bilashvili 2014. Fishing capacity of the southeastern Black Sea anchovy fishery. Journal of Marine Systems 135: 160169. DOI: 10.1016/j.jmarsys.2013.04.013

Ceyhan, V. and H. Gene 2014. Productive efficiency of commercial fishing: evidence from the Samsun Province of Black Sea, Turkey. Turkish Journal of Fisheries and Aquatic Sciences 14(2): 309-320. DOI: 10.4194/1303-2712-v14_2_02

Charnes, A., W.W. Cooper and E. Rhodes 1978. Measuring the efficiency of decision-making units. European Journal of Operational Research, 2: 429-444. DOI: https://doi.org/10.1016/03772217(78)90138-8

Coelli, T.J., D.S.P. Rao, C.J. O'Donnell and G.E. Battese 2005. An Introduction to Efficiency and Productivity Analysis. Springer Science \& Business Media.

Collier, T.C., A. Mamula and J. Ruggiero 2014. Estimation of multi-output production functions in commercial fisheries. Omega 42(1): 157-165.

Cooper, W.W., L.M. Seiford and K. Tone 2006. Introduction to Data Envelopment Analysis and its Uses: with DEA-solver Software and References. Springer Science \& Business Media.

Desai, A., S.J. Ratick and A.P. Schinnar 2005. Data Envelopment Analysis with Stochastic Variations in Data. Socio-Economic Planning Sciences 39(2): 147-164. https://doi.org/10.1016/j.seps.2004.01.005

Dupont, D.P., R.Q. Grafton, J. Kirkley and D. Squires 2002. Capacity utilization measures and excess capacity in multi-product privatized fisheries. Resource and Energy Economics 24(3): 193-210. 
Duy, N.N. and O. Flaaten 2016. Efficiency analysis of fisheries using stock proxies. Fisheries Research 181: 102-113. https://doi.org/10.1016/j.fishres.2016.04.006.

El-Demerdash, B.E., I.A. El-Khodary and A.A. Tharwat 2016. A stochastic data envelopment analysis model considering variation in input and output variables. International Journal of Data Envelopment Analysis and Operations Research 2(1): 1-6. DOI: 10.12691/ijdeaor-2-1-1

Emrouznejad, A., G.L. Yang 2018. A survey and analysis of the first 40 years of scholarly literature in DEA: 1978-2016. Socio-Economic Planning Sciences 61(1): 4-8.

FAO, 2017. Small-scale fisheries, FAO Fisheries and Aquaculture Department, Rome. accessed 15/9/2017. http://www.fao.org/fishery/ssf/en.

FAO 2000. Report of the technical consultation on measurement of fishing capacity. FAO Fishing Report No. 615. Food and Agriculture Organization of the Untied Nation, Rome.

Färe, R., C.K. Lovell and S. Grosskopf 1994. Production Frontiers. Cambridge University Press. Cambridge

Gigentika, S., T.W. Nurani, S.H. Wisudo, and J. Haluan 2016. Fishing capacity and technical efficiency of tuna fisheries in Kupang, Indonesia. Aquaculture, Aquarium, Conservation \& Legislation, International Journal of the Bioflux Society (AACL Bioflux) 9(4): 854-863.

Guyader, O. and F. Daures 2005. Capacity and scale inefficiency: application of data envelopment analysis in the case of the French Seaweed fleet. Marine Resource Economics 20(4): 347-365. https://doi.org/10.1086/mre.20.4.42629482

Guttormsen, A.G. and K.H. Roll 2011. Technical efficiency in a heterogeneous fishery: the case of Norwegian groundfish fisheries. Marine Resource Economics 26(4): 293-307. https://doi.org/10.5950/0738-1360-26.4.293

Holland, D.S. and S.T. Lee 2002. Impacts of random noise and specification on estimates of capacity derived from data envelopment analysis. European Journal of Operational Research 137(1): 10-21.

Johansen, L. 1968. Production functions and the concept of capacity. Recherches récentes sur la fonction de production, Collection, Economie mathématique et économétrie 2: 52-62.

Kirkley, J.E., D. Squires, M.F. Alam and H.O. Ishak 2003. Excess capacity and asymmetric information in developing country fisheries: the Malaysian purse seine fishery. American Journal of Agricultural Economics 85(3): 647-662. https://doi.org/10.1111/1467-8276.00462

Kirkley, J., C.J.M. Paul and D. Squires 2002. Capacity and capacity utilization in commonpool resource industries. Environmental and Resource Economics 22(1-2): 71-97. https://doi.org/10.1023/A:1015511232039

Madau, F., L. Idda and P. Pulina 2009. Capacity and economic efficiency in small-scale fisheries: evidence from the Mediterranean Sea. Marine Policy 33(5): 860-867.

MAF (Ministry of Agriculture and Fisheries), 2017. Fisheries Statistics Year Book 2016. Ministry of Agriculture and Fisheries, Sultanate of Oman.

MECA (Ministry of Environment and Climate Affairs), 2015. $5^{\text {th }}$ National Report to the Convention on Biological Diversity (CBD) 2014. Ministry of Environment and Climate Affairs, Sultanate of Oman.

MNE (Ministry of National Economy), 2007a. Seventh Five-Year Development Plan 20062010, National Centre for Statistics and Information, Muscat.

MNE (Ministry of National Economy), 2007b. Long-Term Development Strategy (1996-2020): Vision for Oman's Economy (Oman 2020), National Centre for Statistics and Information, Muscat.

Odeck, J. 2000. Assessing the relative efficiency and productivity growth of vehicle inspection services: An application of DEA and Malmquist indices. European Journal of Operational Research 126(3): 501-514. https://doi.org/10.1016/S0377-2217(99)00305-7

Pascoe, S. and D. Tingley 2006. Economic capacity estimation in fisheries: A non-parametric ray approach. Resource and Energy Economics 28(2): 124-138.

https://doi.org/10.1016/j.reseneeco.2005.06.003

Pham, T.D.T., H.W. Huang and C.T. Chuang 2014. Finding a balance between economic performance and capacity efficiency for sustainable fisheries: Case of the Da Nang gillnet fishery, Vietnam. Marine Policy 44: 287-294.

Pomeroy, R.S. 2012. Managing overcapacity in small-scale fisheries in Southeast Asia. Marine Policy 36(2): 520-527. https://doi.org/10.1016/j.marpol.2011.10.002 
Purcell, S.W. and R.S. Pomeroy 2015. Driving small-scale fisheries in developing countries. Frontiers in Marine Science 2, Article 44: 1-7. https://doi.org/10.3389/fmars.2015.00044

Ross, A. and C. Droge 2002. An integrated benchmarking approach to distribution center performance using DEA modeling. Journal of Operations Management 20(1): 19-32. https://doi.org/10.1016/S0272-6963(01)00087-0

Salas, S., R. Chuenpagdee, J.C. Seijo and A. Charles 2007. Challenges in the assessment and management of small-scale fisheries in Latin America and the Caribbean. Fisheries Research 87(1): 5-16. https://doi.org/10.1016/j.fishres.2007.06.015

Shen, S. and Shen, Z. 2013. Analysis of fishery production efficiency based on the three-stage DEA. pp. 289-298. In: Proceedings of the 2nd International Conference on Green Communications and Networks 2012 (GCN 2012), Volume 1. Springer, Berlin, Heidelberg. https://doi.org/10.1007/978-3-642-35419-9_34

Tidd, A.N., C. Reid, G.M. Pilling and S.J. Harley 2016. Estimating productivity, technical and efficiency changes in the Western Pacific purseseine fleets. ICES Journal of Marine Science 73(4): 1226-1234. https://doi.org/10.1093/icesjms/fsv262

Tingley, D., S. Pascoe and L. Coglan 2005. Factors affecting technical efficiency in fisheries: stochastic production frontier versus data envelopment analysis approaches. Fisheries Research 73(3): 363-376. https://doi.org/10.1016/j.fishres.2005.01.008

Tingley, D., S. Pascoe and S. Mardle 2003. Estimating capacity utilisation in multi-purpose, multi-metier fisheries. Fisheries Research 63(1): 121-134. https://doi.org/10.1016/S0165-7836(02)00283-7

Tsitsika, E.V., C.D. Maravelias, P. Wattage and J. Haralabous 2008. Fishing capacity and capacity utilization of purse seiners using data envelopment analysis. Fisheries Science 74(4): 730-735.

DOI: 10.1111/j.1444-2906.2008.01583.x

Vázquez-Rowe, I. and P. Tyedmers 2013. Identifying the importance of the "skipper effect" within sources of measured inefficiency in fisheries through data envelopment analysis (DEA). Marine Policy 38: 387-396. DOI: https://doi.org/10.1016/j.marpol.2012.06.018

Vestergaard, N., D. Squires and J. Kirkley 2003. Measuring capacity and capacity utilization in fisheries: the case of the Danish Gill-net fleet. Fisheries Research 60(2): 357-368. https://doi.org/10.1016/S0165-7836(02)00141-8 Wu, W.W., L.W. Lan and Y.T. Lee 2013. Benchmarking hotel industry in a multi-period context with DEA approaches: A case study. Benchmarking: An International Journal 20(2): 152-168.

https://doi.org/10.1108/14635771311307650

Yang, C. and X. Lou 2016. Technical efficiency study on Japanese marine fisheries applying stochastic frontier analysis and data envelopment analysis approaches. International Journal of Fisheries and Aquatic Studies 4 (4): 135-141.

Zervopoulos, P. 2012. Dealing with small samples and dimensionality issues in data envelopment analysis.

http://mpra.ub.uni-muenchen.de/39226/

Zibaei, M. 2012. Technical efficiency analysis of fisheries: toward an optimal fleet capacity. Sustainable Agriculture Research 1(1): 96-102. http://dx.doi.org/10.5539/sar.v1n1p96

Zhang, Y. and R. Bartels 1998. The effect of sample size on the mean efficiency in DEA with an application to electricity distribution in Australia, Sweden and New Zealand. Journal of Productivity Analysis 9(3): 187-204. https://doi.org/10.1023/A:1018395303580 